\title{
Choroid Plexus Cysts
}

Jose A. Lopez, MD, and Douglas Reich, MD

Background: Research shows that there is an association between choroid plexus cysts and aneuploidy. Family physicians treating prenatal patients should understand the management of this sonographic finding.

Objective: To determine the epidemiology, pathophysiology, and management of prenatal choroid plexus cysts.

Case report: A 23-year-old patient, gravida 1, para 0, was seen at an inner city Family Medicine health center for prenatal care. A screening ultrasonogram performed at 16 weeks of gestation showed bilateral choroid plexus cysts approximately $5 \mathrm{~mm}$ in diameter. The patient declined amniocentesis. Maternal serum triple screen markers (maternal serum $\alpha$-fetoprotein, human chorionic gonadotropin, and estriol) were all normal, as was the level II sonogram at 20 weeks and the fetal echocardiogram at 28 weeks. At birth the baby was found to be normal after a clinical assessment was performed.

Methods: A review of the literature using MEDLINE with the search strategy of choroid plexus, choroid plexus fetus/fetal, choroid plexus management, choroid plexus treatment, and choroid plexus epidemiology. (J Am Board Fam Med 2006;19:422-5.)

The first description of choroid plexus cyst (CPC) on antenatal sonogram appeared in the literature in $1984,{ }^{1}$ and soon after its association with trisomy 18 was described. ${ }^{2}$ Despite the publication of numerous articles, controversy still remains concerning appropriate management. Prenatal karyotyping is recommended when maternal serum screening markers are abnormal and abnormalities are found on sonogram..$^{3-12}$ However, the presence of CPC on sonogram without other abnormalities is a cause of controversy and should be recognized in early pregnancy as an important issue which must be addressed with proper management and care.

\section{Case History}

A 23-year-old female patient, gravida 1, para 0, was seen at an urban community-based Family Medicine health center for prenatal care. A screening sonogram performed at 16 weeks of gestation showed bilateral CPC approximately $5 \mathrm{~mm}$ in diameter. The patient, a Jewish immigrant from Russia, declined amniocentesis. Maternal serum triple screen markers (maternal serum $\alpha$-fetoprotein, hu-

Submitted 25 September 2005; revised 16 February 2006; accepted 28 February 2006.

From Wyckoff Heights Medical Center, Brooklyn, NY.

Conflict of interest: none declared.

Corresponding author: Jose A. Lopez, MD, Wyckoff Heights Medical Center, 374 Stockholm Street, Brooklyn, NY 11237 (E-mail: JOL9033@nyp.org). man chorionic gonadotropin, estriol) were all nor$\mathrm{mal}$, as well as the sonogram at 20 weeks of gestation and the fetal echocardiogram at 28 weeks of gestation. At birth, the baby was found to have normal Apgar scores and to be in healthy condition.

\section{Discussion \\ Epidemiology}

In the second trimester, the incidence of CPC has been estimated by several population studies to be $1 \%, 3,4,13-19$ and other studies have found the incidence to vary from $0.18 \%$ to $3.6 \% .^{20,21}$ Despite the low incidence, CPC has clinical implications for aneuploidy because of an association of choroid plexus with trisomy $18^{2,5-12,22}$ and trisomy 21. 4,10,13,19,22-24 Researchers have been more concerned with trisomy 18 because the prevalence of $\mathrm{CPC}$ for fetuses with trisomy 21 and for the general population are the same. ${ }^{13,23,24}$ Prenatal sonography in $44 \%$ to $50 \%$ of pregnancies with trisomy 18 show CPC, ${ }^{15,16}$ whereas only $1.4 \%$ of pregnancies with trisomy 21 show CPC. ${ }^{13}$ Approximately three fourths of abnormal fetal karyotypes associated with choroid plexus cysts are trisomy 18 and one fourth are trisomy $21 .^{23}$ Thus, trisomy 18 has greater clinical relevance than trisomy 21 .

\section{Pathophysiology}

Choroid plexus develops at approximately 6 weeks gestation. At the onset, a bulge from the medial wall of the lateral ventricle becomes covered with 
pseudo-stratified epithelium and then lobulated with villi. The cells at this time change from cuboid to columnar epithelium. As the villi grow and become entangled, a cystic space is formed, which traps cerebral spinal fluid. Choroid plexus produces cerebrospinal fluid and is seen prominently in the posterior horn of the lateral ventricle in secondtrimester ultrasounds. In the 9th week of gestational age, the choroid plexus begins producing cerebrospinal fluid leading to expansion of the ventricular system. Most villi form at 13 to 18 weeks of gestation, and the cysts regress by 28 weeks of gestation. Frequently, fluid accumulates and results in the formation of cysts, which can be detected on sonogram. ${ }^{25-28}$

\section{Management}

The American College of Obstetrics and Gynecology (ACOG) advises careful anatomic survey of the fetus in cases of isolated CPC. If no anomalies are observed on ultrasound then amniocentesis should be offered but not encouraged. If a mother presents with risk factors for trisomy 18 , such as advanced age, abnormal triple marker screen, and abnormal fetal abnormalities on sonogram, amniocentesis may be recommended. ${ }^{29}$

In an effort to guide clinical practice, research has focused on 3 factors that modify the risk for trisomy 18. These factors are physical characteristics on sonography, the role of maternal age, and serum markers. Consensus has not been established due to the variability in study design, selection of study population, and lack of consistency in ultrasound technique.

Agreement has been established that ultrasound characteristics of CPC, such as bilaterality, size, number, complexity, and resolution, are not related to the risk of aneuploidy. ${ }^{10,30-33}$ However, cysts with diameters less than $5 \mathrm{~mm}$ may not be linked with trisomy $18,{ }^{14,19}$ and large cysts in excess of 10 mm may impart a higher risk. ${ }^{16,34}$ Furthermore, the risk for trisomy 18 when compared with normal births has been shown to increase with the presence of CPC without any other sonographic abnormalities, ie, isolated choroid plexus. Studies have estimated the likelihood ratio from 3.5 to 9 and risk from $1 / 30$ to $1 / 477 .{ }^{35-38}$ A risk estimate for trisomy 18 from 18 studies with over 3000 fetuses in an unselected population was found to be 1 in 189 (95\% CI: 1 in 125 to 1 in 385). In the same study population, there were only 2 cases of trisomy $21 .{ }^{39}$
In a screened high-risk population, 16 studies found the risk for trisomy 18 to be 1 in 128 (95\% CI: 1 in 86 to 1 in 250) with 6 cases of trisomy 21 in 2049 cases of CPC. ${ }^{30}$ These studies guide physicians to be concerned about trisomy 18 but not trisomy 21 . In our case, CPC was the only abnormal finding on sonogram.

In an attempt to further refine the risk estimate, many researchers have developed formulas that utilize age as a factor in estimating risk for trisomy 18 coupled with a finding of isolated CPC. Likelihood ratios of 3 to 9 have been found with an age cutoff from 33 to $37.6,36,37,40,41$ The results from these studies are principally based on reviews with nonspecific inclusion criteria, and the risk adjustment is dependent on interpretation of the literature. In our case, the patient's risk would have been low because of young maternal age.

Despite numerous studies on the effects of maternal age and sonographic findings on the risk for trisomy 18 , few authors have investigated the use of triple serum markers as an adjunct to sonography. ${ }^{33,40,42}$ One study found that the risk of trisomy 18 for a fetus with isolated CPC (1/270) approaches the amniocentesis risk $(1 / 200)$ at age $37 .{ }^{40}$ Another author assessed when biochemical testing might be a valuable adjunct to ultrasonography and concluded that triple-screen testing, together with a targeted ultrasonographic examination, followed by selective amniocentesis, is adequate to detect the chromosomal abnormalities in fetuses with choroid plexus cysts. ${ }^{43}$ More studies need to assess the value of serum markers in determining the risk of trisomy 18 with isolated CPC. The normal results of the triple markers in the current case would not have modified the risk of aneuploidy in a fetus.

Amniocentesis is recommended when CPC is found with other abnormalities on sonogram, ${ }^{2-12}$ but no consensus has been reached on cases of isolated CPC. Recommendations are based on the comparison of the risk of amniocentesis to the calculated risk of trisomy 18 with or without modifying risk factors. Because of a lack of agreement in the medical literature, recommendations have varied. Many research studies have concluded that an isolated CPC is not an indication for genetic testing, ${ }^{44-47}$ whereas many other studies recommend genetic testing. ${ }^{4,11,19,22,48}$ Interestingly, an individualized risk method had been proposed using maternal age, presence of an isolated CPC, and serum markers as modifying risk factor. If 
risk is greater than $1 / 200$, amniocentesis is offered. Clearly, more research is needed to accurately estimate the risk of trisomy 18 .

In the current case, the risk for aneuploidy was low because of young maternal age, isolated CPC as the only sonogram finding, and normal serum markers. This clinical scenario is similar for many primary care physicians who practice prenatal care. Physicians providing prenatal care to women, who have children later in life after completing their education or starting their careers, need to consider maternal age in any risk assessment.

Studies on isolated CPC lead to inconsistent results because of the variability in research design and analysis. These factors include a retrospective study design, differences in patient population, differences in sonogram expertise, and failure to consider factors that impact aneuploidy, such as maternal age and serum screening results in many studies. A longitudinal study would provide a greater level of evidence, which would respond to many questions regarding modifying risk factors and management of isolated CPC. Unfortunately, the low incidence would make such a study impractical.

\section{Conclusion}

Primary care physicians should approach CPC in a practical manner. CPC detected on ultrasound at 18 to 20 weeks warrants an additional sonogram of the fetal hands, heart, and central nervous system by an experienced sonographer to search for other abnormalities. ${ }^{49}$ The nature of the cyst should be fully explained to the patient, as well as the risks associated with trisomy 18 and 21, along with modifying risk factors, such as maternal age, serum markers, and other sonogram findings. The option for genetic testing should be explained along with its risks and benefits. Consultation with a genetic specialist or high-risk obstetrician may be indicated. ${ }^{19}$ Despite the low incidence of isolated CPC on prenatal sonogram, physicians must take into consideration the risk of aneuploidy; furthermore, physicians must understand the controversy regarding medical management of CPC. Until further studies are completed, the risks and benefits of genetic testing must be weighed against the risk of aneuploidy in light of modifying risk factors.

\section{References}

1. Chudleigh P, Pearce JM, Campbell S. The prenatal diagnosis of transient cysts of the fetal choroid plexus. Prenat Diagn 1984;4:135-7.

2. Nicolaides K, Rodeck CN, Gosden CM. Rapid karyotyping in non-lethal fetal malformations. Lancet 1986;1:2823-7.

3. Nava S, Godmilow L, Reeser S, Ludomirsky A, Donnenfeld AE. Significance of sonographically detected second-trimester choroid plexus cysts: a series of 211 and a review of the literature. Ultrasound Obstet Gynecol 1994;4:448-51.

4. Kupferminc MJ, Tamura RK, Sabagha RE, Parilla BV, Cohen LS, Pergament E. Isolated choroid plexus cyst(s): an indication for amniocentesis. Am J Obstet Gynecol 1994;171:1068-71.

5. Chitty L. Choroid plexus cysts: the need for further study: Ultrasound Obstet Gynecol 1994;4:444-5.

6. Snijders RJ, Shawa L, Nicolaides KH. Fetal choroid plexus cysts and trisomy 18: assessment of risk based on ultrasound findings and maternal age. Prenat Diagn 1994;14:1119-27.

7. Oettinger M, Odeh M, Korenblum R, Markovits J. Antenatal diagnosis of choroid plexus cyst: suggested management. Obstet Gynecol Surv 1993;48:635-9.

8. Chitkara U, Cogswell C, Norton K, et al. Choroid plexus cysts in the fetus: a benign anatomic variant or pathologic entity? Report of 41 cases and review of the literature. Obstet Gynecol 1988;72:185-9.

9. Platt LD, Carlson DE, Medearis AL, et al. Fetal choroid plexus cysts in the second trimester of pregnancy: a cause for concern? Am J Obstet Gynecol 1991;164:1652-6.

10. Perpignano MC, Cohen HL, Klein VR, et al. Fetal choroid plexus cysts: between the small cyst. Radiology 1992;182:715-7.

11. Zerres K, Schuler H, Gembruch U, Badl R, et al. Chromosomal finding in fetuses with prenatally diagnosed cysts of the choroid plexus. Hum Genet 1992;89:301-4.

12. Fitzsimmons J, Wilson D, Pascoe-Mason J, et al. Choroid plexus cysts in fetus with trisomy 18 . Obstet Gynecol 1989;73:257-60.

13. Bromley B, Lieberman R, Benacerraf BR. Choroid plexus cysts: not associated with Down syndrome. Ultrasound Obstet Gynecol 1996;8:232-5.

14. Chitty LS, Chudleigh P, Wright E, Campbell S, Pembrey M. The significance of choroid plexus cysts in an unselected population: results of a multi-center study. Ultrasound Obstet Gynecol 1998;12:391-7.

15. Denis E, Dufour P, Valat AS, et al. Choroid plexus cysts and risks of chromosome anomalies. Review of the literature and proposed management. J Gynecol Obstet Biol Reprod 1998;27:144-9.

16. Gray DL, Winborn RC, Suessen TL, Crane JP. Is genetic amniocentesis warranted when isolated cho- 
roid plexus cysts are found? Prenat Diagn 1996;16: 983-90.

17. Morcos CL, Platt LD, Carlson DE, Gregory KD, Greene NH, Korst LM. The isolated choroid plexus cyst. Obstet Gynecol 1998;92:232-6.

18. Reinsch RC. Choroid plexus cyst—association with trisomy: prospective review of 16,059 patients. Am J Obstet Gynecol 1997;176:1381-3.

19. Walkinshaw S, Pilling D, Spriggs A. Isolated choroid plexus cyst - the need for routine offer of karyotyping. Prenat Diagn 1994;14:663-7.

20. Clark SL, DeVore GR, Sabey PL. Prenatal diagnosis of cysts of the fetal choroid plexus. Obstet Gynecol 1988;72:585-6.

21. Chinn DH, Miller EI, Workty LM, Towers CV. Sonographically detected choroid plexus cysts: frequency and association with aneupolidy. J Ultrasound Med 1991;10:255-8.

22. Porto M, Murata Y, Warneke LA, Keejan KA. Fetal choroid plexus cysts: an independent risk factor for chromosomal anomalies. J Clin Ultrasound 1993;21: 103-8.

23. Gupta JK, Cave M, Lilford RJ, et al. Clinical significance of fetal choroid plexus cysts. Lancet 1995;346: 724-9.

24. Leonardi MR, Wolfe HM, Lanouette JM, et al. The apparently isolated choroid plexus cyst: importance of minor abnormalities in predicting the risk for aneuploidy. Fetal Diagn Ther 1998;13:49-52.

25. Morcos CJ, Lawrence DP, Carlson DE, et al. The isolated choroid plexus cysts. Obstet Gynecol 1998; 92:232-6.

26. Dziegielewska KM, Ek J, Habgood MD, Saunders NR. Development of choroid plexus. Microsc Res Tech 2001;52:5-20.

27. Kennedy KA, Carey JC. Choroid-plexus cyst: significance and current management practices. Semin Ultrasound CT MR 1993;14:23-30.

28. Sharmony R. Fetal choroid plexus cysts-is a genetic evaluation indicated? Prenat Diagn 1997;17:519-24.

29. ACOG Practice Bulletin. Clinical management guidelines for obstetrician-gynecologists. Prenatal diagnosis of fetal chromosomal abnormalities. Obstet Gynecol. 2001;97(Suppl):1-12.

30. Walkinshaw S. Fetal choroid plexus cysts: are we there yet? Prenat Diagn 2000;20:657-62.

31. Shields LE, Uhrich SB, Easterling TR, Cyr DR, Mack LA. Isolated fetal choroid plexus cysts and karyotype analysis: is it necessary? J Ultrasound Med 1996;15:389-94.

32. Peleg D, Yankowitz J. Choroid plexus cysts and aneuploidy. J Med Genet 1998;35:554-7.

33. Brown T, Kliewer MA, Hertzberg BS, et al. A role for maternal serum screening in detecting chromosomal abnormalities in fetuses with isolated choroid plexus cysts: a prospective multicentre study. Prenat Diagn 1999;19:405-10.

34. Ostlere SJ, Irving HC, Lilford RJ. Fetal choroid plexus cyst: a report of 100 cases. Radiology 1990; 175:753-5.

35. Snijders RJ, Sebire NJ, Nicolaides KH. Maternal age and gestational age-specific risk for chromosomal defects. Fetal Diagn Ther 1995;10:356-67.

36. Gupta JK, Khan KS, Thornton JG, Lilford RJ. Management of fetal choroid plexus cysts. Br J Obstet Gynaecol 1997;104:881-6.

37. Yoder PR, Sabbagha RE, Gross SJ, Zelop CM. The Second-trimester fetus with isolated choroid plexus cysts: a meta-analysis of risk of trisomies 18 and 21. Obstet Gynecol 1999;93:869-72.

38. Ghidini A, Strobelt N, Locatelli A, Maraian E, Piccoli MG, Pergani P. Isolated fetal choroid plexus cyst: role of ultrasonography in establishment of the risk of trisomy 18. Am J Obstet Gynecol 2000;182: 972-7.

39. Benacerraf BR, Harlow B, Figoletto FD. Are choroid plexus cysts an indication for second trimester choroid plexus cysts. Am J Obstet Gynecol 1990;162: 1000-6.

40. Gratton RJ, Hogge WA, Aston CE. Choroid plexus cysts and trisomy 18: risk modification based on maternal age and multiple markers screening. Am J Obstet Gynecol 1996;175:1493-7.

41. Choong S, Meagher S. Management of choroid plexus cysts in the mid-trimester fetus. Aust NZ J Obstet Gynaecol 1999;39:7-11.

42. Sullivan A. Giudice T, Vavelidis F, Thiagarajah S. Choroid plexus cysts: is biochemical testing a valuable adjunct to targeted ultrasonography? Am J Obstet Gynecol 1999;181:260-5.

43. Gross SJ, Shulman LP, Tolley EA, et al. Isolated fetal choroid plexus cysts and trisomy 18: a review and meta-analysis. Am J Obstet Gynecol 1995;172: $83-7$.

44. Lilford RJ. Fetal choroid cysts. Lancet 1995;346: 1361-2.

45. Nadel AS, Bromley BS, Frigoletto FD, Estroff JA, Benacerraf BR. Isolated choroid plexus cysts in the second trimester fetus: is amniocentesis really indicated? Radiology 1992;185:545-8.

46. Donnenfeld AE. Prenatal sonographic detection of isolated fetal choroid plexus cysts: should we screen for trisomy 18? J Med Screen 1995;2:18-21.

47. Donnenfeld AE. Risk and benefit analysis of offering karyotyping for an isolated choroid plexus cyst. Ultrasound Obstet Gynecol 1997;9:67-8.

48. Burrows A, Ramsden GH, Frazer ML. Choroid plexus cysts in the fetal brain, Aust NZ J Obstet Gynecol 1994;34:220.

49. Sepulveda $W$, Lopez-Tenorio J. The value of minor ultrasound markers for fetal aneuploidy. Obstet Gynecol 2001;13:183-91. 